\title{
Early and midterm results of totally endoscopic coronary artery bypass grafting on the beating heart
}

\author{
Changqing Gao, MD, Ming Yang, MD, Yang Wu, MD, Gang Wang, MD, Cangsong Xiao, MD, \\ Yue Zhao, RN, and Jiali Wang, BS
}

\begin{abstract}
Objective: Despite the early introduction of totally endoscopic coronary artery bypass on the beating heart, only a limited number of cases have been performed. The limiting factor has been the concern about safety and graft patency of the anastomosis. This study describes our experience with totally endoscopic coronary artery bypass on the beating heart with robotic assistance and its early and midterm results.
\end{abstract}

Methods: In 365 cases of robotic cardiac operations, 162 patients underwent robotic coronary artery bypass grafting on the beating heart, of whom 60 patients (46 male, 14 female) underwent totally endoscopic coronary artery bypass on the beating heart. The patients' mean age was $56.97 \pm 9.7$ years (33-77 years). Left internal thoracic artery to left anterior descending anastomosis was performed using the U-Clip device.

Results: We completed 58 totally endoscopic coronary artery bypass procedures, in which 16 patients received hybrid procedures. Two patients had conversions to a minithoracotomy. The average left internal thoracic artery harvesting and anastomosis times were $31.3 \pm 10.5$ (18 55) minutes and $11.3 \pm 4.7$ (5 21) minutes, respectively. The mean operating room and operation times were $336.1 \pm 58.5$ (210 580) minutes and $264.8 \pm 65.6(150 \sim 420)$ minutes, respectively. The drainage was $164.9 \pm 83.2(70 \sim 450) \mathrm{mL}$. Before discharge, 50 patients underwent angiography and 8 patients underwent computed tomography angiography, and the study showed that graft patency was $100 \%$. Unexpectedly, the left internal thoracic artery graft developed a collateral branch in 2 patients. After discharge, all patients were followed up by computed tomography angiography. The average follow-up time was $12.67 \pm 9.43$ (1-40) months. One patient had gastric bleeding after surgery.

Conclusions: Totally endoscopic coronary artery bypass on the beating heart is a safe procedure in selected patients and produces excellent early and midterm patency of anastomosis. ( $\mathrm{J}$ Thorac Cardiovasc Surg 2011;142:843-9)

Conventional coronary artery bypass grafting (CABG) provides complete revascularization with excellent long-term results. The current tendency is to perform operations through smaller and smaller incisions to reduce hospital stay and to hasten postoperative recovery. After the introduction of robotic telemanipulators, totally endoscopic coronary artery bypass (TECAB) procedures became feasible in the late 1990s. Loulmet and colleagues ${ }^{1}$ performed the first TECAB procedure on the arrested heart in 1999, and subsequently several investigators reported TECAB on the beating heart. ${ }^{2-7}$ Despite these milestones, only a limited number of cases have been performed worldwide. The limiting factor has been concern about safety and graft patency of the anastomosis. Since 2007, we have performed more than 360

\footnotetext{
From the Minimally Invasive and Robotic Cardiac Surgery Center, Department of Cardiovascular Surgery, PLA General Hospital, Institute of Cardiac Surgery, Beijing, China.

Disclosures: Authors have nothing to disclose with regard to commercial support. Received for publication Nov 22, 2010; revisions received Dec 23, 2010; accepted for publication Jan 24, 2011; available ahead of print March 9, 2011.

Address for reprints: Changqing Gao, MD, Department of Cardiovascular Surgery, PLA General Hospital, Institute of Cardiac Surgery, Beijing, China, 100853 (E-mail: gaochq301@yahoo.com).

$0022-5223 / \$ 36.00$

Copyright (c) 2011 by The American Association for Thoracic Surgery doi:10.1016/j.jtcvs.2011.01.051
}

cases of robotic cardiac surgery. ${ }^{8-11}$ This study describes our single-center and single-surgeon experience with TECAB on the beating heart with robotic assistance and its early and midterm results.

\section{MATERIALS AND METHODS}

From 2007 to 2010, with approval from the institutional review board of PLA General Hospital and informed consent, we performed 365 cases of robotic cardiac operations with the da Vinci S Surgical System (Intuitive Surgical Inc, Sunnyvale, Calif) in 365 patients, 162 of whom underwent robotically assisted CABG on the beating heart, including hybrid approaches for patients with multivessel diseases, in which 60 patients (46 male and 14 female) underwent TECAB on the beating heart. The mean age of patients undergoing TECAB was $56.97 \pm 9.7$ (range, 33-77) years.

\section{Patient Selection}

Patients were considered eligible for enrollment in the study if deemed appropriate candidates for first-time single-vessel left internal thoracic artery (LITA) to left anterior descending (LAD) myocardial revascularization and their coronary angiogram showed total occlusion or significant stenosis in LAD or double- or triple-vessel disease in which LAD involved total or subtotal occlusion and non-LAD lesions were amenable to percutaneous coronary intervention (PCI).

Exclusion criteria were patients with a history of left lung surgery, unstable hemodynamics, severe chronic obstructive pulmonary disease with inability to tolerate 1-lung anesthesia, and an extremely dilated heart. 


$$
\begin{aligned}
& \text { Abbreviations and Acronyms } \\
& \begin{aligned}
\text { CABG } & =\text { coronary artery bypass grafting } \\
\text { CTA } & =\text { computed tomography angiography } \\
\text { ITA } & =\text { internal thoracic artery } \\
\text { LAD } & =\text { left anterior descending } \\
\text { LITA } & =\text { left internal thoracic artery } \\
\text { MIDCAB } & =\text { minimally invasive direct coronary } \\
& \text { artery bypass } \\
\text { OPCAB } & =\text { off-pump coronary artery bypass } \\
\text { PCI } & =\text { percutaneous coronary intervention } \\
\text { RCA } & =\text { right coronary artery } \\
\text { TECAB } & =\text { totally endoscopic coronary artery } \\
& \text { bypass }
\end{aligned}
\end{aligned}
$$

\section{Procedures}

After routine induction of anesthesia, double-lumen intubation was carried out for single right lung ventilation. External defibrillator patches were placed on the chest, and the patient was positioned supine with the left chest elevated 30 degrees with the aid of a small bolster under the left chest. The operative side arm with protective padding hung loosely supported by a sheet. In female patients, the breast was positioned medially and after sterile skin preparation was secured by an adhesive sheet during the draping.

The console surgeon placed the camera and the instrument ports. Three 0.8 - to $1.0-\mathrm{cm}$ incisions were made in the third, fifth, and seventh intercostal spaces 2 to $3 \mathrm{~cm}$ medial to the anterior axillary line (Figure 1). After deflation of the left lung, a camera port was inserted through the middle incision and carbon dioxide insufflation was initialed and maintained at an average of 6 to $8 \mathrm{~mm} \mathrm{Hg}$, which may be increased to $12 \mathrm{~mm} \mathrm{Hg}$ as long as patients are able to maintain satisfactory hemodynamic status. A 30-degree angle upward camera was inserted, and the thoracic cavity and the location and course of the LITA were examined. The left and the right instrument ports were inserted. The surgical cart with 4 arms was brought in and docked to the camera and the instrument arm ports.

The robotic system was used to harvest the LITA completely from the subclavian vein to the LITA bifurcation in a totally skeletonized fashion.

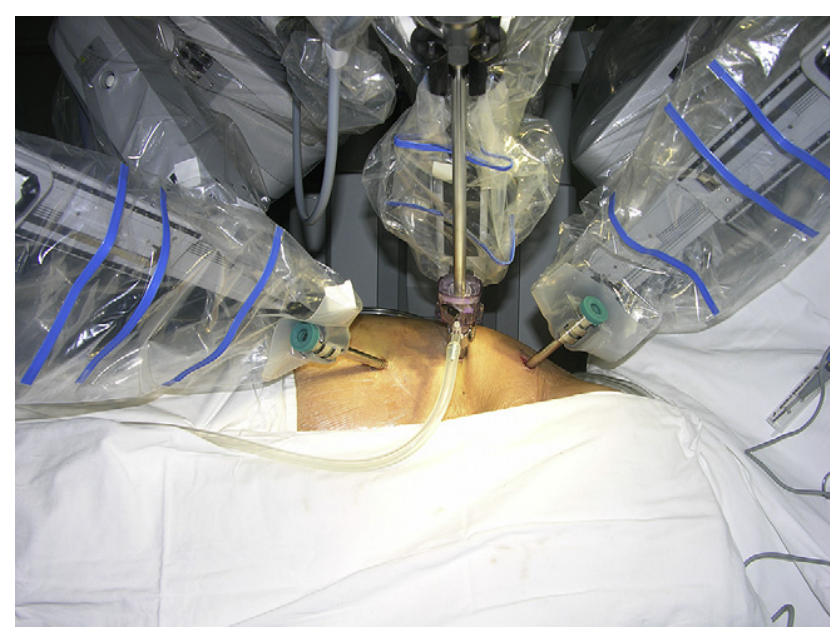

FIGURE 1. The da Vinci S Surgical System (Intuitive Surgical Inc, Sunnyvale, Calif) setup for TECAB surgery.
Hemoclips were used for larger branches, and cautery was used to cauterize and transect the smaller branches. In a few cases, the LITA was harvested with the accompanying veins in case of close proximity of arteries and veins. The LITA was left attached to the chest wall with the connecting areolar tissue to prevent it from hanging over the pericardium. Pericardiotomy was performed, the pericardium over the apex of the left ventricle was left intact to prevent herniation of the heart, and the target vessel was identified using a 30-degree angle downward camera.

The da Vinci S 12-mm cannula was inserted into the thoracic cavity close to the left midclavicular line at the subcostal margin. All the anastomosis supplies were passed into the chest through this port. After systemic heparinization, the distal LITA was skeletonized completely and partially transected obliquely leaving a small toe section attached. Five S18-U-Clips were put outside-in in the far side of the partial transection of the LITA (Figure 2). The LITA was fully transected and secured to the epicardial fat to maintain the LITA location and orientation. After the console surgeon took active control to position the endostabilizer at the LAD to apply epicardial tension, the LAD was dissected and occluded proximally and distally with saddle loops. The LAD arteriotomy was created and anastomosed to the LITA using an interrupted parachuting technique. First, the $5 \mathrm{U}$-clips were put inside-out in the far side of the LAD, and then, 3 more U-clips were put in the near side, and the internal thoracic artery (ITA) was parachuted onto the coronary artery (Figures 3 and 4). The saddle loop occluders were removed to check the anastomosis. Intravenous lidocaine infusion was used during pericardiotomy and coronary anastomosis to minimize ventricular arrhythmia. After protamine administration, the graft flow was measured by the Medi-Stim (MediStim AS, Oslo, Norway) transit time probe. All accessories were removed from the ports, a chest tube was placed, the robotic system was removed, and all wounds were closed (Figure 5).

\section{RESULTS}

Fifty-eight TECAB procedures were successfully completed, in which 16 patients received a stent in the right coronary artery (RCA) or circumflex artery 4 or 5 days after the TECAB in a hybrid procedure. All ITAs were harvested without incidence of injury and were suitable for TECAB. A total of 57 patients received in situ LITA to LAD anastomosis, and 1 patient received in situ right ITA to RCA anastomosis, which was explored through an infraxiphoid

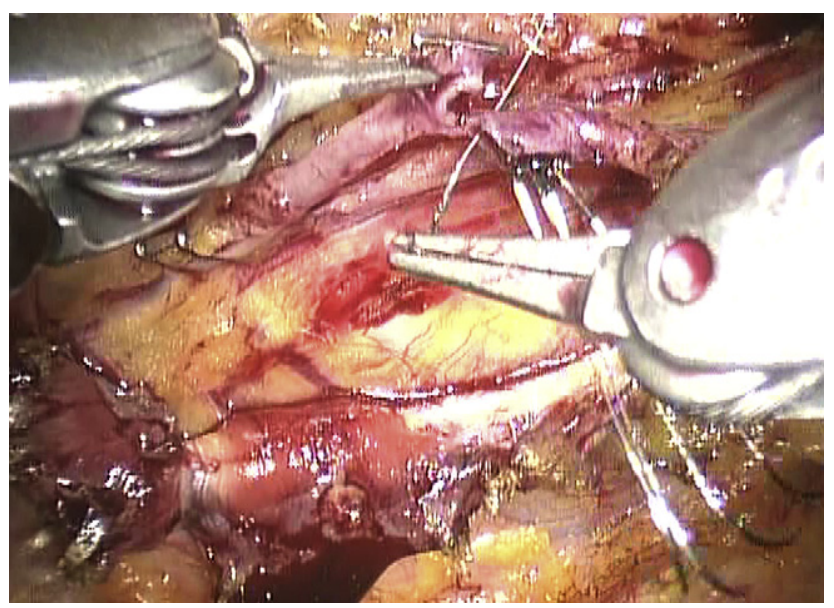

FIGURE 2. Five U-clips are put outside-in in the far side of the partial transection of the LITA. 


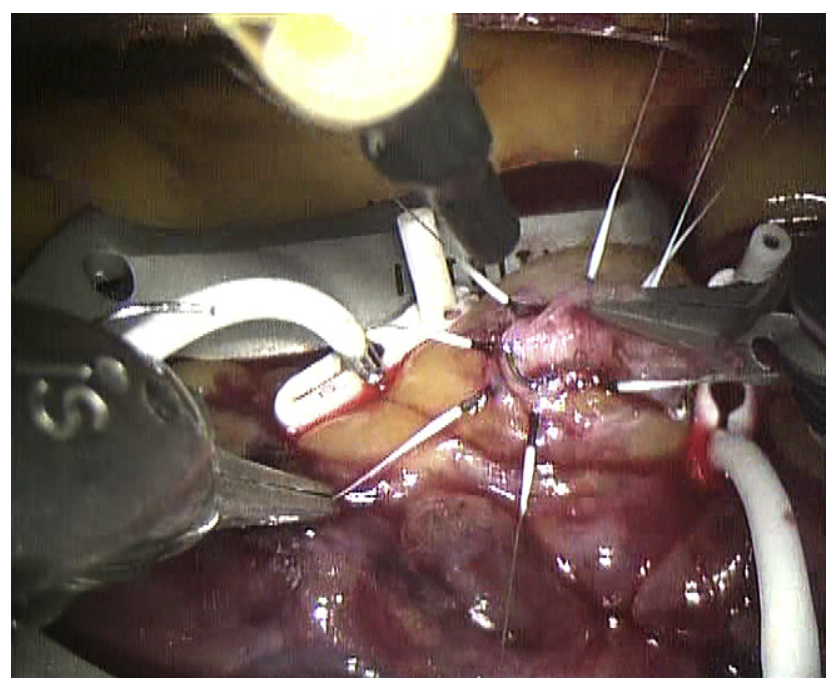

FIGURE 3. Eight U-clips are inserted.

incision. Two patients had conversions to minithoracotomy during the operation. Intraoperative flow was measured in all cases, and the average graft flow was $35.8 \pm 18.2(10 \sim 103)$ $\mathrm{mL} / \mathrm{min}$. The average LITA harvesting, coronary occlusion, and anastomosis times were $31.3 \pm 10.5(18 \sim 55)$ minutes, $22.6 \pm 9.6$ (7-40) minutes, and $11.3 \pm 4.7(5 \sim 21)$ minutes, respectively. The mean operating room time was $336.1 \pm$ 58.5 (210 580) minutes, and the mean operation time was $264.8 \pm 65.6(150 \sim 420)$ minutes. The learning curve is shown in Figure 6, $A$ and $B$. The average chest drainage was $164.9 \pm 83.2(70 \sim 450) \mathrm{mL}$. Troponin-Tand creatine kinase/creatine kinase-myoglobin levels were within normal range. The average intubation time was $8.29 \pm 4.17$ hours, the average intensive care unit stay was $1.5 \pm 1.4$ days, and the average hospital stay was $5.0 \pm 1.5$ days, $17 \%$ of patients received blood or blood product infusion, and chest drainage was $264.9 \pm 183.2 \mathrm{~mL}$. One patient required reex-

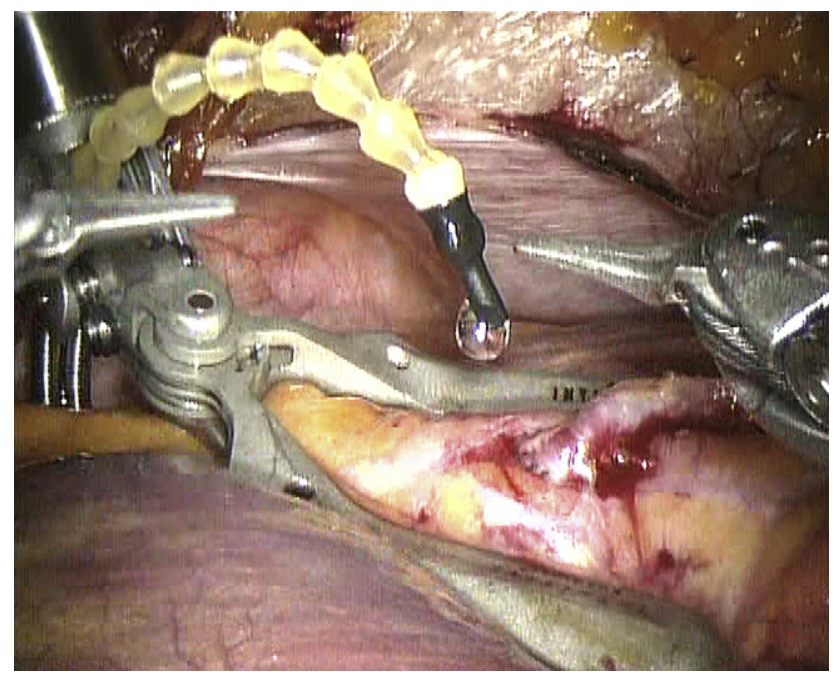

FIGURE 4. The ITA is parachuted onto the coronary artery.

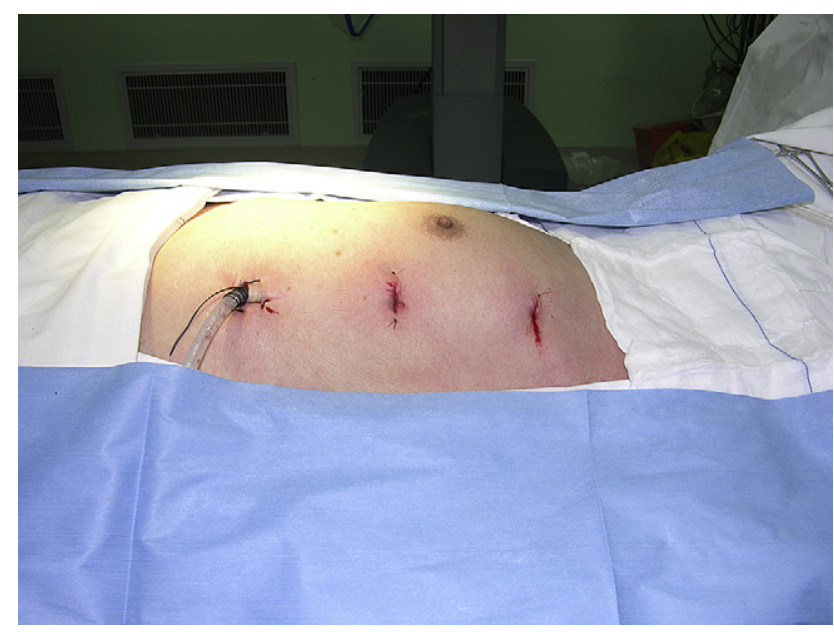

FIGURE 5. The wounds are closed.

ploration for bleeding after surgery. No patient had angina after surgery. Before discharge, 50 patients $(86 \%)$ underwent coronary angiography. The remaining 8 patients underwent computed tomography angiography (CTA), and both angiography and CTA showed $100 \%$ graft patency (Figure 7). The competitive flow in the LITA to LAD graft was found on coronary angiography after surgery in 2 patients. Unexpectedly, angiography showed that LITA graft in the middle segment developed a collateral branch in 2 patients (Figure 8); however, they were asymptomatic. After discharge, all patients were followed up by CTA at 3 , 6 , and 12 months, and the study showed $100 \%$ graft patency. One patient had 50\% stenosis in the anastomosis, 1 patient had low density in the ITA graft on computed tomography follow-up, and 1 patient had gastric bleeding 6 months after surgery. The average follow-up time was $12.67 \pm 9.43$ (1-40 months). No other complications were found.

\section{Intraoperative Exclusion and Conversion}

The intraoperative exclusion criteria were used for technical or anatomic reasons that were not identified preoperatively. For example, dense pleural adhesions, intramyocardial coronary target, or hemodynamic intolerance of $\mathrm{CO}_{2}$ insufflation. The intraoperative conversions were defined as patients in whom a beating heart TECAB procedure in progress had to be abandoned and converted to a small anterior thoracotomy approach because the surgeon could not proceed endoscopically, for reasons such as patient instability, LITA injury, unsatisfactory anastomosis, excessive bleeding, or robotic system malfunction.

\section{DISCUSSION}

Recent technologic advances have brought completely new instruments into the heart surgery armamentarium and enabled the development of minimally invasive 


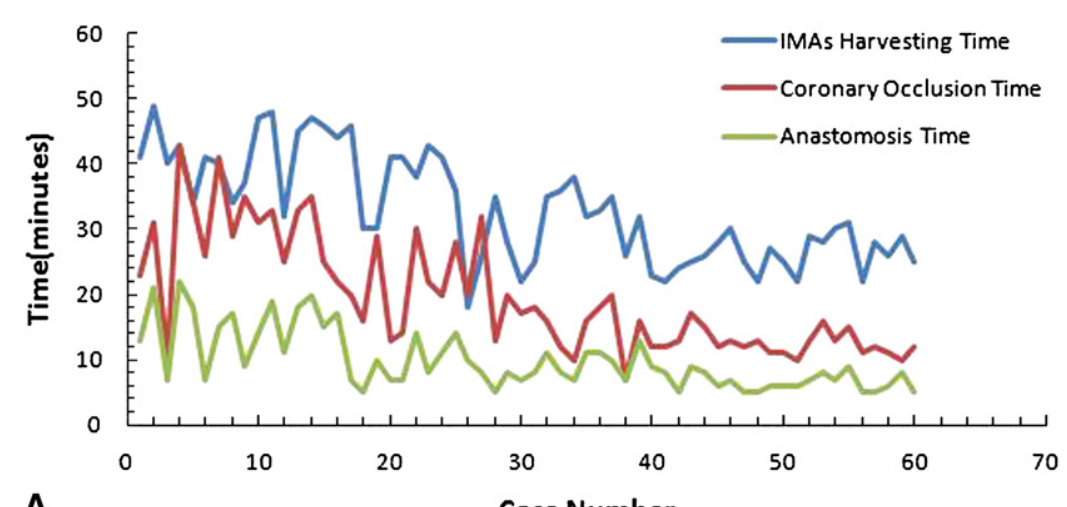

A

Case Number

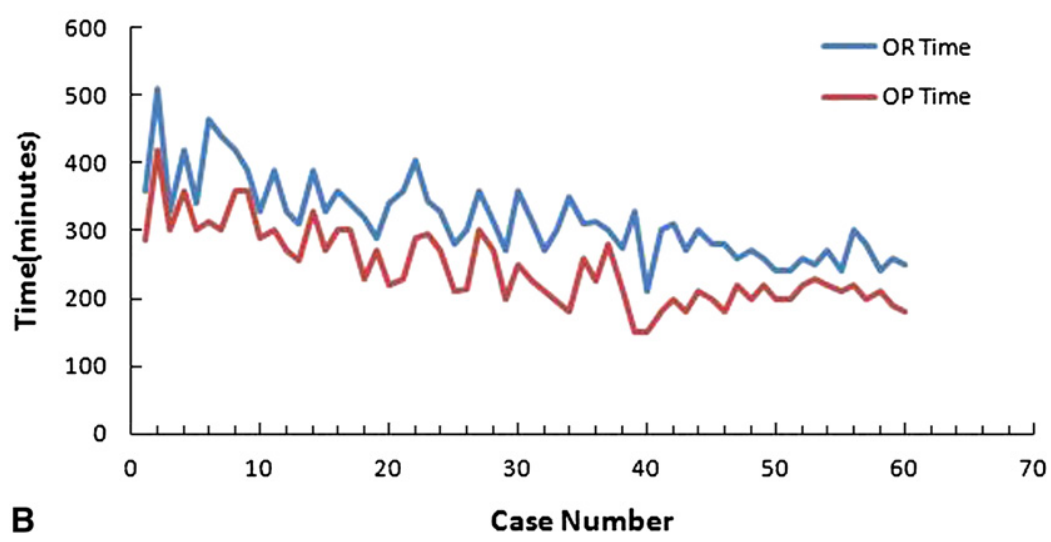

FIGURE 6. A, LITA harvesting, coronary occlusion, and anastomosis times. B, Mean operating room and operation times. ITA, Internal thoracic artery; $O R$, operating room; $O P$, operation.

operative techniques. With the introduction of the endoscopic stabilizer (Medtronic Inc, Minneapolis, Minn/Intuitive Surgical Inc), the use of computer-assisted surgical systems, and the development of advanced telemanipulation devices, the heart surgeon has had the possibility to perform cardiac surgery totally endoscopically. However, only a limited number of cases of TECAB have been performed worldwide. ${ }^{2-7,12-15}$ The limiting factor has been concern about safety and graft patency of the anastomosis.

Since 2007, the author, as console surgeon, has performed more than 360 cases of various types of robotic cardiac operations, ${ }^{8-11}$ of which 162 patients underwent robotically assisted CABG on the beating heart, including hybrid approaches for patients with multivessel diseases. Of these 162 patients, 102 underwent minimally invasive direct coronary artery bypass (MIDCAB) surgery on the beating heart and 60 underwent TECAB on the beating heart.

As we know, the ultimate goal of minimally invasive CABG is to perform the entire anastomosis in a closed chest, to avoid the deleterious effects of cardiopulmonary bypass, and to minimize the incision and surgical trauma. Moreover, the superiority of ITA as a conduit has been well established for long-term patency and event-free survival. ${ }^{16,17}$ TECAB on the beating heart has brought minimally invasive $\mathrm{CABG}$ close to this goal.
TECAB on the beating heart is technically demanding, and there are several critical issues that we have to emphasize for successful surgery. Although beating heart TECAB

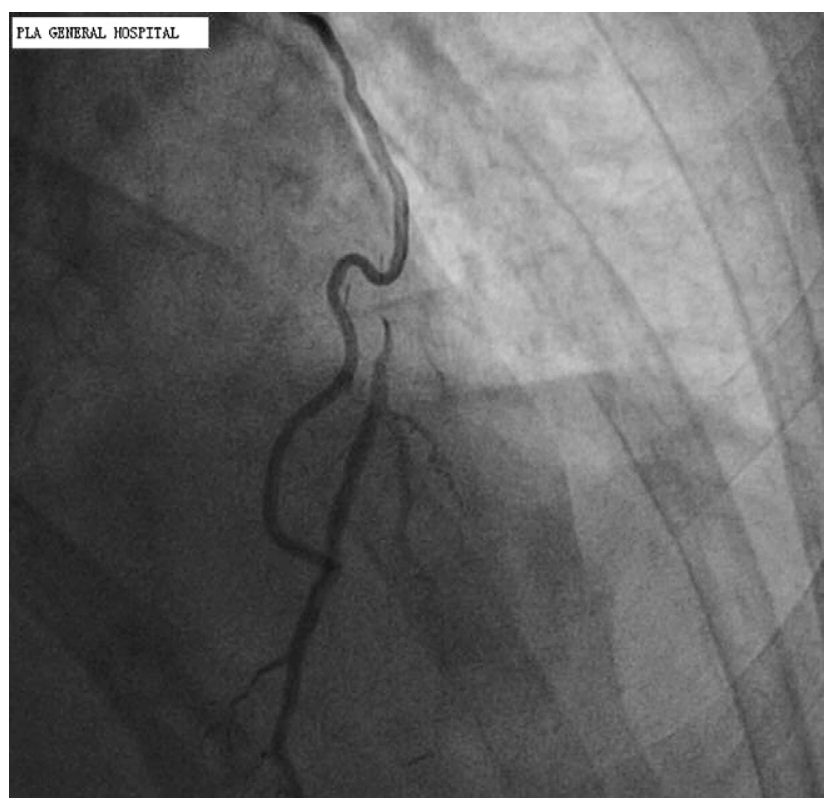

FIGURE 7. Angiography shows graft patency. 


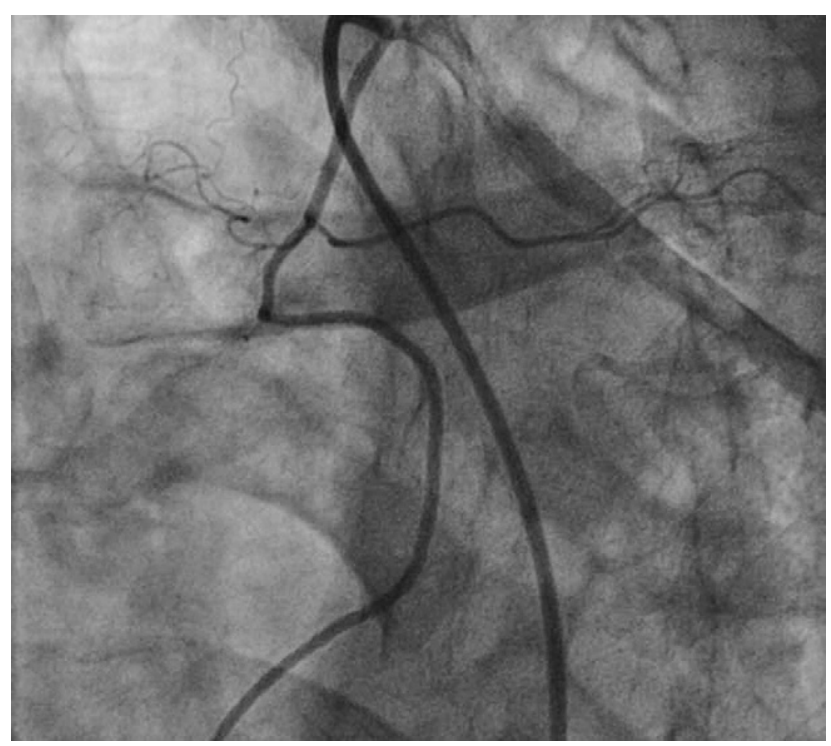

FIGURE 8. Angiography shows collateral branch.

is feasible and safe, ${ }^{7,11}$ proper planning and patient selection are critical for success, and grafting strategy should never be compromised to complete revascularization. First, the patients' comorbidities should be considered. All patients with pulmonary disease or poor ejection fraction should be excluded because poor hemodynamics or low cardiac output could develop during the procedure as the result of $\mathrm{CO}_{2}$ insufflation, which decreases venous return. In addition, cardiac stabilization could further decrease cardiac output. Second, the location, quality, and trajectory of the target vessel should be considered. This is more important in TECAB than in open surgery because the artery sometimes can be difficult to find if the vessel is located in the fat or intramyocardial vessel. In our group, 1 case was converted to MIDCAB because of intramyocardial LAD during operation. If the vessel is calcified, it could be more difficult to perform the anastomosis robotically. Therefore, we think that diffuse calcified and intramyocardial vessels should be exclusion criteria for TECAB procedure. Third, the quality of the target vessel is important. In off-pump coronary artery bypass $(\mathrm{OPCAB})$ surgery, the bigger the vessel, the easier the anastomosis and better the result, and totally occluded arteries are ideal target vessels because there is rarely any ischemia during vessels occlusion and the time to perform the coronary anastomosis is not an issue. ${ }^{18}$ However, in using the da Vinci Surgical System, we have found that the diameter of the vessel is not a problem for anastomosis because a 3-dimensional $10 \times$ magnified view and EndoWrist instruments (Intuitive Surgical Inc) allow for precise placement of the U-Clips as long as the quality of the target vessel is good. We also found the quality of totally occluded vessel usually is not as ideal as we expected.
Therefore, we believe that the quality of the target vessel is of paramount importance.

Suturing the anastomosis is the most demanding part of TECAB on the beating heart because under the $10 \times$ magnification even the slightest movement of the target vessel could compromise surgical manipulation, and it is sometimes difficult to assess the quality of the vessel wall because of the lack of tactile feedback. Therefore, finding the right position for placing a stitch could be awkward. Interrupted anastomosis reduces the possibility of purse stringing of a continuous suture and helps to overcome the lack of tactile feedback inherent with the da Vinci Surgical System. ${ }^{7}$ Moreover, by using intravascular ultrasonography, it has been proven that interrupted anastomosis with surgical U-Clips is more compliant than anastomosis with running sutures. ${ }^{19}$ We also found that a big bite of U-Clips at the outside of the incision of target vessel is helpful for hemostasis. Because the heart is not decompressed by using cardiopulmonary bypass and the space in the thoracic cavity is limited, $\mathrm{CO}_{2}$ pressure may be increased above the suggested value up to $15 \mathrm{~mm} \mathrm{Hg}$ as long as the heart is filled sufficiently and contractility is not impaired. We must emphasize that the endostabilizer should not be compressed too much on heart to avoid compromising contractility, and a lighter touch rather than heavy compression can also minimize the bouncing effect of the beating heart. In addition, preconditioning ischemia may be useful to facilitate longer anastomotic time in instances of less than $80 \%$ to $90 \%$ stenosis in a large proximal LAD. It is import to remember to rely on visional cues. Therefore, we believe that robotic cardiac surgery should be conducted by surgeons with extensive surgical experience in open techniques.

Optimal anesthesia will minimize occurrence of ischemia in the target coronary arteries with significant stenosis. Continuous intravenous nitroglycerin drip is useful during the procedure and for 24 hours postoperatively. The crucial issue of anesthesia for the surgery is to deal with the hemodynamic compromise, hypoxia, and hypercarbia relevant to 1-lung ventilation, and intrathoracic insufflation of $\mathrm{CO}_{2}$ with positive pressure. ${ }^{20}$

The results of the MIDCAB procedure with harvesting the thoracic vessel and coronary anastomosis performed through a minithoracotomy have been established. ${ }^{21}$ In our group, 2 patients required conversion to MIDCAB during the operation. One patient had an intramyocardial LAD, in whom we found the intramyocardial LAD was difficult to anastomose to the LITA robotically. One patient had a diffuse calcified RCA, in whom we anastomosed the right ITA to diffuse the RCA robotically; however, blood flow was not satisfactory. We therefore explored the anastomosis with an infraxiphoid incision. The intraoperative exclusion or conversion was not considered as failure of therapy because all these patients would have required an open approach. Therefore, when it is necessary, we recommend conversion 
to a MIDCAB procedure, which allows excellent results without long operating times. ${ }^{22}$ In our department, 102 patients underwent robotic MIDCAB on the beating heart with excellent follow-up results.

PCI is an established technique for coronary revascularization; therefore, hybrid revascularization is an alternative therapy for multivessel coronary artery disease in selected patients in whom PCI is a poor option because of LAD disease location. ${ }^{11,23}$ In our study, 16 patients underwent hybrid revascularization in a staged approach with excellent results. ${ }^{11}$

Robotic cardiac surgery requires real teamwork, and surgeons must overcome a substantial learning curve before mastering TECAB on the beating heart. Our learning curve is shown in Figure 6, $A$ and $B$. The median time for ITA harvesting and operation significantly decreased with surgical experience in terms of number of operations, but ITA harvest time decreased more rapidly than anastomosis time with experience. Our learning curve was truncated because the author, as console surgeon, simultaneously performed a large volume of various kinds of other robotic cardiac surgeries with the same team in a relatively short time $e^{8-11}$ and had experience of more than 1500 cases of OPCAB surgery. ${ }^{24}$ Since we started our robotic surgical program, our robotic team has not changed. Our experience showed that with a well-trained robotic team and after a substantial learning curve, we could achieve optimal results for TECAB on the beating heart.

In our group, $86 \%$ of patients underwent coronary angiography and the remaining $14 \%$ (8 patients) underwent CTA before discharge because of patient refusal to undergo angiography, and the studies showed $100 \%$ graft patency. Angiography showed that the LITA graft in the middle segment had a collateral branch in 2 patients (Figure 8), which was difficult to explain because the ITA was harvested in a totally skeletonized fashion. What was surprising is that the residual branches appeared to be located in the middle segment of LITA, rather than in the highest anterior intercostal branch of the ITA in both cases. Neither of these patients has had stress ischemia to the LAD distribution so far during follow-up. Our policy is that the skeletonized ITA is harvested from the first rib to the distal bifurcation to avoid this occurrence. After discharge, all patients were followed up by CTA, which is easily tolerated and accepted by the patients, although conventional coronary angiography remains the gold standard for evaluation of graft patency. ${ }^{25}$ Graft patency was assessed along the whole body of the graft and at the anastomotic site. Patency of graft and anastomosis was assessed according to Fitzgibbon and colleagues ${ }^{26}$ : A (patent) $=$ excellent graft with unimpaired runoff; B (partially patent) = stenosis reducing caliber of anastomoses or trunk to less than $50 \%$ of the grafted coronary artery; $\mathrm{O}$ (occlusion) $=$ no blood flow. Although all grafts followed up by CTA were found to be patent in our group, there were 2 patients with type B. One patient had $50 \%$ stenosis in the anastomotic site, and 1 patient had low density in the ITA graft on computed tomography follow-up. The competitive flow in the LITA to LAD graft was also found in 2 patients on coronary angiography after surgery. The reason might not be critical stenosis in the LAD anastomosed to the arterial graft (LITA). One patient had only $75 \%$ stenosis in the proximal LAD, and 1 patient had approximately $85 \%$ stenosis in the proximal LAD before surgery. Our graft patency is comparable to the results for conventional $\mathrm{CABG}$ and $\mathrm{OPCAB}$ surgery.

\section{Study Limitations}

This was a retrospective study of a highly select group of patients, performed in a single center by a single surgeon, which are study limitations.

\section{CONCLUSIONS}

TECAB on the beating heart is a safe procedure for coronary bypass grafting in selected patients and produces excellent early and midterm patency of anastomosis and surgical results. The procedure should be conducted by surgeons with extensive surgical experience in open techniques and requires a stable and well-trained robotic team and overcoming a substantial learning curve.

\section{References}

1. Loulmet D, Carpentier A, d'Attellis N, Berrebi A, Cardon C, Ponzio O, et al. Endoscopic coronary artery bypass grafting with the aid of robotic assisted instruments. J Thorac Cardiovasc Surg. 1999;118:4-10.

2. Falk V, Diegeler A, Walther T, Jacobs S, Raumans J, Mohr FW. Total endoscopic off-pump coronary artery bypass grafting. Heart Surg Forum. 2000;3:29-31.

3. de Canniere D, Wimmer-Greinecker G, Cichon R, Gulielmos V, VanPraet F, Seshadri-Kreaden U, et al. Feasibility, safety, and efficacy of totally endoscopic coronary artery bypass grafting: multicenter European experience. $J$ Thorac Cardiovasc Surg. 2007;134:710-6.

4. Bonatti J, Schachner T, Bonaros N, Öhlinger A, Danzmayr M, Jonetzko P, et al. Technical challenges in totally endoscopic robotic coronary artery bypass grafting. J Thorac Cardiovasc Surg. 2006;131:146-53.

5. Bolton JW, Connally J. Results of a phase one study on robotically assisted myocardial revascularization on the beating heart. Ann Thorac Surg. 2004;78:154-8.

6. Argenziano M, Katz M, Bonatti J, Srivastava S, Murphy D, Poirier R, et al. Results of the prospective multicenter trial of robotically assisted totally endoscopic coronary artery bypass grafting. Ann Thorac Surg. 2006;81:1666-75.

7. Srivastava S, Gadasalli S, Agusala M, Kolluru R, Barrera R, Quismundo S, et al. Beating Heart totally endoscopic coronary artery bypass. Ann Thorac Surg. 2010; 89:1873-80.

8. Gao C, Yang M, Wang G, Wang JL, Li LX, Zhao Y, et al. Totally robotic internal mammary artery harvest and beating heart coronary artery bypass. Chin J Surg. 2007;45:1414-6.

9. Gao C, Yang M, Wang G, Wang JL, Xiao CS, Li LX, et al. Robotic atrial septal defect repair: preliminary experience with da Vinci S system. Chin J Thorac Cardiovasc Surg. 2007;23:298-300.

10. Gao C, Yang M, Wang G, Wang J. Totally robotic resection of myxoma and atrial septal defect repair. Interact Cardiovasc Thorac Surg. 2008;7:947-50.

11. Gao C, Yang M, Wu Y, Wang G, Xiao CS, Liu HB, et al. Hybrid coronary revascularization by endoscopic robotic coronary artery bypass grafting on beating heart and stent placement. Ann Thorac Surg. 2009;87:737-41.

12. Dogan S, Aybek T, Anderssen E, Byhahn C, Mierdl S, Westphal K, et al. Totally endoscopic coronary artery bypass grafting on cardiopulmonary bypass with robotically enhanced telemanipulation: report of forty-five cases. $J$ Thorac Cardiovasc Surg. 2002;123:1125-31. 
13. Bonatti J, Schachne T, Bernecker O, Chevtchik O, Bonaros N, Ott H, et al. Robotic totally endoscopic coronary artery bypass: program development and learning curve issues. J Thorac Cardiovasc Surg. 2004;127:504-10.

14. Cichon R, Kappert U, Schneider J, Schramm I, Gulielmos V, Tugtekin S, et al. Robotic-enhanced arterial revascularization for multivessel coronary artery disease. Ann Thorac Surg. 2000;70:1060-2.

15. Kappert U, Schneider J, Cichon R, Gulielmos V, Matschke K, Tugtekin S, et al. Wrist-enhanced instrumentation: moving toward totally endoscopic coronary artery bypass grafting. Ann Thorac Surg. 2000;70:1105-8.

16. Rankin J, Tuttle R, Wechsler A, Teichmann T, Glower D, Califf R. Techniques and benefits of multiple internal mammary artery bypass at 20 years of followup. Ann Thorac Surg. 2007;83:1008-15.

17. Sabik J, Lytle B, Blackstone E, Houtaling P, Cosgrove D. Comparison of saphenous vein and internal thoracic artery graft patency by coronary system. Ann Thorac Surg. 2005;79:544-51.

18. Folliguet T, Dibie A, Philippe F, Larrazet F, Slama M, Laborde F. Roboticallyassisted coronary artery bypass grafting. Cardiol Res Pract. 2010;2010:175450.

19. Hamman B, White C. Interrupted distal anastomosis: the interrupted "porcupine" technique. Ann Thorac Surg. 2004;78:722-4.

20. Wang G, Gao C, Zhou Q, Chen T. Anesthesia management for robotically assisted endoscopic coronary artery bypass grafting on beating heart. Innovations (Phila). 2010;5:291-4
21. Kappert U, Cichon R, Schneider J, Gulielmos V, Ahmadzade T, Nicolai J, et al Technique of closed chest coronary artery surgery on the beating heart. Eur J Cardiothorac Surg. 2001;20:765-9.

22. Srivastava S, Gadasalli S, Agusala M, Kolluru R, Naidu J, Shroff M, et al Use of bilateral internal thoracic arteries in CABG through lateral thoracotomy with robotic assistance in 150 patients. Ann Thorac Surg. 2006;81: 800-6.

23. Bonatti J, Schachner T, Bonaros N, Jonetzko P, Ohlinger A, Ruetzler E, et al Simultaneous hybrid coronary revascularization using totally endoscopic lef internal mammary artery bypass grafting and placement of rapamycin eluting stents in the same interventional session: the combination pilot study Cardiology. 2008;110:92-5.

24. Gao C, Li BJ, Xiao CS, Wang G, Jiang SL, Wu Y, et al. Clinical analysis of 1018 cases of coronary artery bypass grafting. Chin J Surg. 2005;43:929-32.

25. Gao C, Liu ZY, Li BJ, Xiao CS, Wu Y, Wang G, et al. Comparison of graft patency for off-pump and conventional coronary arterial bypass grafting using 64-slice multidetector spiral computed tomography angiography. Interact Cardiovasc Thorac Surg. 2009;8:325-9.

26. Fitzgibbon GM, Kafka HP, Leach AJ, Keon WJ, Hooper D, Burton JR. Coronary bypass graft fate and patient outcome: angiographic follow-up of 5,065 grafts related to survival and reoperation in 1,388 patients during 25 years. $J$ Am Coll Cardiol. 1996;28:616-26. 